\title{
Dengue Infection - prevalence and seasonal variation among patients attending a tertiary care hospital at Chamarajanagar, Karnataka
}

\author{
Sathish J. V. ${ }^{1}$, Trupti B. Naik,", P. Vamsi Muni Krishna ${ }^{3}$, Asmabegaum Biradar ${ }^{4}$ \\ ${ }^{\mathbf{1}}$ Associate Professor, ${ }^{2}$ Assistant Professor, ${ }^{3}$ Tutor, ${ }^{4}$ Assistant Professor, Dept. of Microbiology, Chamarajanagar Institute of \\ Medical Sciences, Karnataka, ${ }^{4}$ Al- Ameen Medical College, Vijaypura, Karnataka, India
}

*Corresponding Author:

Email: truptinaik01@gmail.com

\begin{abstract}
Introduction: Dengue fever is an emerging acute febrile illness caused by arboviruses and presenting with wide spectrum of clinical manifestations ranging from self-limiting asymptomatic infection to severe fatal infection like Dengue hemorrhagic shock with unpredictable outcome. It is endemic in India and in recent years it is appearing in the form of epidemics especially during rainy season.

Objectives

1. To determine seroprevalence of dengue virus among clinically suspected cases.

2. To determine the seasonal variation of dengue infection in the study setting.

3. To study the demographic profile of dengue positive patients.

Materials and Methods: A cross sectional study was done at a tertiary care hospital, Chamarajanagar using secondary data which were maintained in the microbiology laboratory registers, for clinically suspected dengue patients reported to the hospital from January- December 2017. Prevalence was estimated by analyzing data for the results of both NS1antigen and IgM antibody by ELISA tests and any variations in disease reporting by gender, age and season were assessed. Statistical analysis was done using WHO Epi info software version 3.5.4.

Results: A total of 2213 serum samples were analyzed during the study period. Out of which 475 samples $(21.46 \%)$ were found positive for dengue infection either by NS1 or IgM ELISA. The proportion of dengue cases was higher in monsoon season with maximum rate of positivity in August (55.37\%). Paediatric population was the most common affected group (30.33\%).

Conclusion: The present study confirms that dengue is mainly a disease of rainy season and also identifies certain vulnerable groups for effective planning of interventions.
\end{abstract}

Keywords: Dengue, IgM, NS1, Seasonal variation.

\section{Introduction}

Dengue is an acute arboviral infection with potential fatal complications. Dengue is an endemic disease worldwide. According to estimates of the World Health Organization (WHO), around two fifths of the world's population in tropical and subtropical countries are at constant risk of contracting this infection. ${ }^{1}$ Dengue is endemic in many parts of India and recently in the last few years many places have even experienced epidemics. ${ }^{2-4}$ The first evidence of occurrence of Dengue fever in the country was reported in 1956 from Vellore district in Tamil Nadu followed by the first epidemic in Kolkata during 1963-64. ${ }^{5}$ Unplanned urbanization, lifestyle changes and migration of the population from rural to urban areas leading to lack of proper sanitation facilities and improper water storage practices have resulted in an increased burden of dengue in recent times. ${ }^{6}$

Dengue fever is caused by dengue virus, a positive stranded RNA virus in the genus Flavivirus, belonging to family Flaviviridae. ${ }^{7}$ Till now, dengue fever was believed to be caused by four different serotypes that share antigenic relationships (DENV-1, DENV-2, DENV-3 and DENV-4). The fifth variant DENV-5 has been isolated in October 2013 which follows the sylvatic cycle unlike the other four serotypes which follow the human cycle. ${ }^{8}$

Principle vectors of transmission for Dengue infection are arthropods of the Aedes genre, especially Aedes aegypti and Aedes albopictus. In tropical areas, maximum transmission of disease occurs in the months of rainfall ${ }^{9}$ owing to increased breeding of vectors in various water collection sites like old tyres, coolers, old earthenware pots, coconut shells etc. ${ }^{10}$ Density of mosquito population will be high (3-4 female mosquitoes per house) during the rainy season as compared the dry season (1-2 female mosquitoes per house). ${ }^{11}$

Diagnostic techniques like isolation of virus by cell culture and nucleic acid detection by reverse transcriptase polymerase chain reaction are time consuming and require costly laboratory setups. Hence in resource limited settings, detection of NS1 antigen and $\mathrm{IgM} / \mathrm{IgG}$ antibodies specific to virus remains as important diagnostic parameters. ${ }^{12}$

Since there is no specific treatment or vaccine for dengue till date, prevention and control of the disease mainly depend upon epidemiological surveillance that provides reliable estimates of the disease, thereby guiding in implementation of effective vector-control 
measures. With this background, the present study was carried out to determine the epidemiological determinants and seasonal variation in dengue infection which could help in rendering adequate control measures.

\section{Aims and Objectives}

1. To determine seroprevalence of dengue virus among clinically suspected cases.

2. To determine the seasonal variation of dengue infection in the study setting.

3. To study the demographic profile of dengue positive patients.

\section{Materials and Methods}

The present cross-sectional study was conducted at a tertiary care hospital of Chamarajanagar Institute of Medical Sciences, Chamarajanagar using secondary data which was maintained in the microbiology laboratory registers, of clinically suspected dengue cases reported to various inpatient and out-patient departments of the hospital for a period of one year from January -December 2017 after obtaining prior permission from the head of the Institute. Prevalence was estimated by analyzing data for the results of both NS1antigen and IgM antibody by ELISA tests and any variations in disease reporting by gender, age and season were assessed.

Approximately $5 \mathrm{ml}$ of blood samples were collected from all the suspects as a part of the routine laboratory work and the sera were separated and tested for the Dengue NS1 antigen and IgM antibody by ELISA methods. According to WHO criteria samples of patient $<5$ days of fever were tested for NS1Ag by tulipqualisa and $\geq 5$ days of fever were tested for the presence of dengue specific $\operatorname{IgM}$ antibodies by using MAC ELISA, developed and commercialized by NIV (National Institute of Virology), Pune, and recommended by National Vector Borne Disease control programme. Manufacturer's instructions were followed strictly while performing the ELISA. Values were calculated and results were interpreted as per manufacturer's guidelines.

\section{Statistical analysis}

Data was analysed using WHO Epi info software version 3.5.4. Observations were presented as frequency and percentage distribution. Relevant descriptive statistics like frequency and percentage were calculated for presentation of data.

\section{Results}

Fig. 1 illustrates seroprevalence of Dengue infection. Among 2213 clinically suspected cases, 475 $(21.46 \%)$ were found to be positive for dengue infection either by NS1 or IgM ELISA in the present study.
Table 1 Department wise distribution of dengue suspects. Out of total samples in our study, majority i.e. $1495(67.55 \%)$ were from out-patient department and the rest from in patient department as seen in table.

Table 2 and Fig. 2 Of the 475 total positive cases of dengue, the proportion of cases was almost equal in both $<15$ years and $16-30$ years age group whereas the rate of seropositivity was highest i.e. $30.33 \%$ in < 15 years age group followed by $16-30$ years $(20.4 \%)$ and the study found statistically significant association between rate of seropositivity and age group ( $\mathrm{p}$ value < $0.05)$.

Table 3 Gender wise distribution of samples of Dengue suspects and positives. Out of 2213 samples tested, $1099(49.66 \%)$ were males and the rest females. Out of the 475 total positive cases of dengue, both the proportion of cases i.e. $248(52.21 \%)$ and the rate of seropositivity i.e. $22.26 \%$ was slightly higher in females as compared to males but there was no significant association between rate of seropositivity and gender ( $p$ value $>0.05)$.

Fig. 3 Seasonal trend showed that suspected cases of Dengue infection started increasing in number from the month of June and peaked in July, August and slowly tapered by September with maximum rate of positivity in August i.e. 170 (55.37\%) followed by July i.e. $196(27.72 \%)$. Serologically confirmed dengue cases were highest i.e. 429 (90.31\%) during the monsoon period compared to other seasons of the year and it was found to be statistically significant ( $\mathrm{p}$ value < $0.05)$.

\section{Discussion}

WHO has declared dengue to be hyper endemic in India and cyclical epidemics of dengue are becoming more frequent. There has been a steady rise in the number of dengue cases reported every year. ${ }^{10,13}$ In the present study out of 2213 clinically suspected cases, $475(21.46 \%)$ were found to be positive for dengue infection either by NS1 or IgM ELISA. The results were congruent with other studies ${ }^{14-18}$ whereas few other studies have reported lower prevalence rate ranging $3-13 \%^{19-22}$ and some studies have reported higher prevalence i.e. $40 \% .^{23-25}$ This difference in seroprevalence could be due to differences in study settings, differences in study periods, differences in sampling techniques, data collection tools as well as differences in sample processing procedure/ techniques.

The present study found maximum positive cases $363(76.41 \%)$ in the age group of $<30$ years similar to the findings of other studies. ${ }^{26,27}$ However, rate of positivity was highest in age group $<15$ years i.e. $30.33 \%$ followed by $16-30$ years i.e. $20.4 \%$ similar to findings of several Indian ${ }^{14-17}$ and international studies. ${ }^{28,29}$ On the contrary few other Indian studies have reported 15 to 45 years as the most affected age

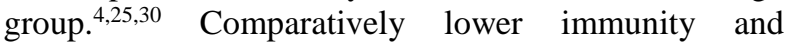
intrinsically more permeable vascular endothelium in 
children render them more susceptible to dengue infections.

A seasonal trend of dengue over one year period was assessed. According to intensity of rainfall, weather data was divided in three periods, namely; pre monsoon period: from February-May, monsoon period: from June-September and post monsoon period: from October-January. In the present study dengue cases were found to be maximum i.e. $429(90.31 \%)$ during monsoon season. Similar pattern is reported by Kauser
MM et al. in Central India, ${ }^{31}$ Madhumati $\mathrm{R}$ et. al. at Bangalore, ${ }^{32}$ Chakravarti A et. al. in Myanmar. ${ }^{33}$ Certain studies showed highest number of cases during Aug-Nov (Maharashtra) ${ }^{14}$ Sept- Oct (Bidar) ${ }^{21}$ October (Delhi), ${ }^{34}$ Oct-Nov (Northeast), ${ }^{35}$ September (Lucknow, Udupi). ${ }^{30,36}$ The reason for monsoon peak in our study may be due to prime occupation of the people being agriculture and increased breeding of vector mosquitoes owing to collection of rain water in domestic and peridomestic areas.

Table 1: Department wise distribution of Dengue samples

\begin{tabular}{|l|c|c|c|}
\hline & Out patient & In patient & Total \\
\hline Gender & No. (\%) & No. (\%) & No. (\%) \\
\hline Male & $748(50.03)$ & $351(48.88)$ & $1099(49.66)$ \\
\hline Female & $747(49.96)$ & $367(51.11)$ & $1114(50.33)$ \\
\hline Total & $\mathbf{1 4 9 5}(\mathbf{6 7 . 5 5})$ & $\mathbf{7 1 8 ( 3 2 . 4 4 )}$ & $\mathbf{2 2 1 3 ( 1 0 0 )}$ \\
\hline
\end{tabular}

Table 2: Age wise distribution of samples of Dengue suspects and positives

\begin{tabular}{|l|c|c|c|}
\hline \multirow{2}{*}{ Age in years } & Suspects & Positives & Rate of positivity \\
\cline { 2 - 4 } & No. (\%) & No. (\%) & \% \\
\hline$<15$ & $600(27.11)$ & $182(38.31)$ & 30.33 \\
\hline $16-30$ & $887(40.08)$ & $181(38.1)$ & 20.4 \\
\hline $31-45$ & $448(20.24)$ & $65(13.68)$ & 14.5 \\
\hline $46-60$ & $202(9.12)$ & $37(7.78)$ & 18.31 \\
\hline$>60$ & $76(3.43)$ & $10(2.1)$ & 13.15 \\
\hline Total & $2213(100)$ & $475(100)$ & 21.46 \\
\hline & $x^{2}=45.74, p$ value $=<0.00001$ \\
\hline
\end{tabular}

Table 3: Gender wise distribution of Dengue suspects and positives

\begin{tabular}{|l|c|c|c|}
\hline Gender & Suspects & Positive & Rate of positivity \\
\hline & No. $(\%)$ & No. $(\%)$ & $(\%)$ \\
\hline Male & $1099(49.66)$ & $227(47.78)$ & 20.65 \\
\hline Female & $1114(50.33)$ & $248(52.21)$ & 22.26 \\
\hline Total & $2213(100)$ & $475(100)$ & 21.46 \\
\hline \multicolumn{4}{|c|}{$\boldsymbol{x}^{2}=0.847, \mathrm{p}$ value $=0.357$} \\
\hline
\end{tabular}

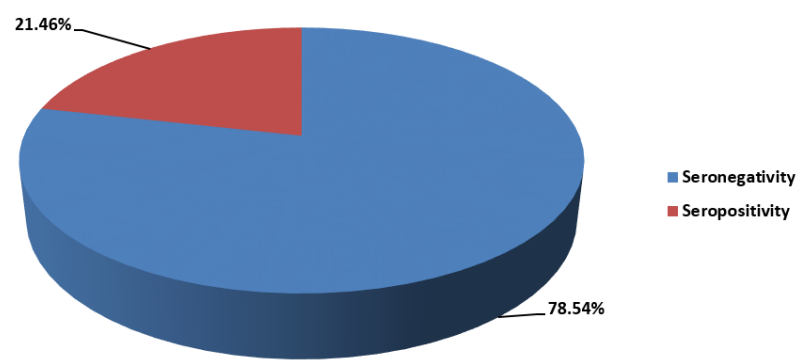

Fig. 1: Seroprevalence of Dengue infection 


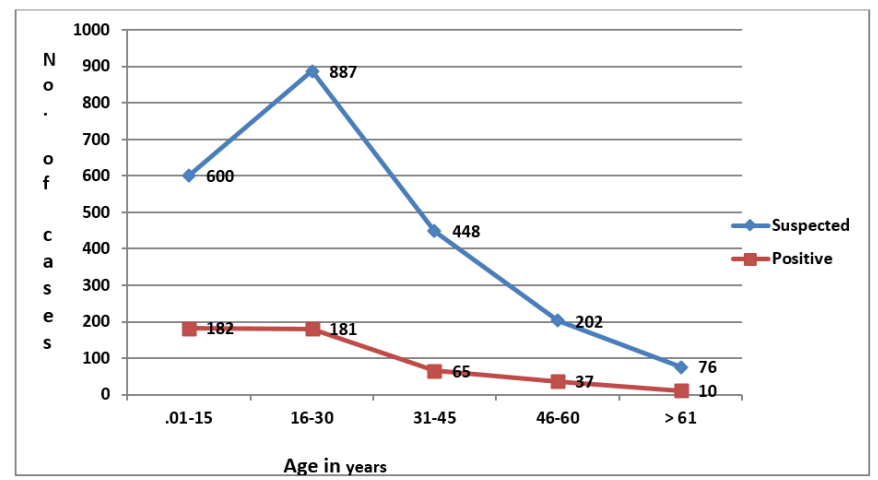

Fig. 2: Age wise distribution of Dengue suspects and positives

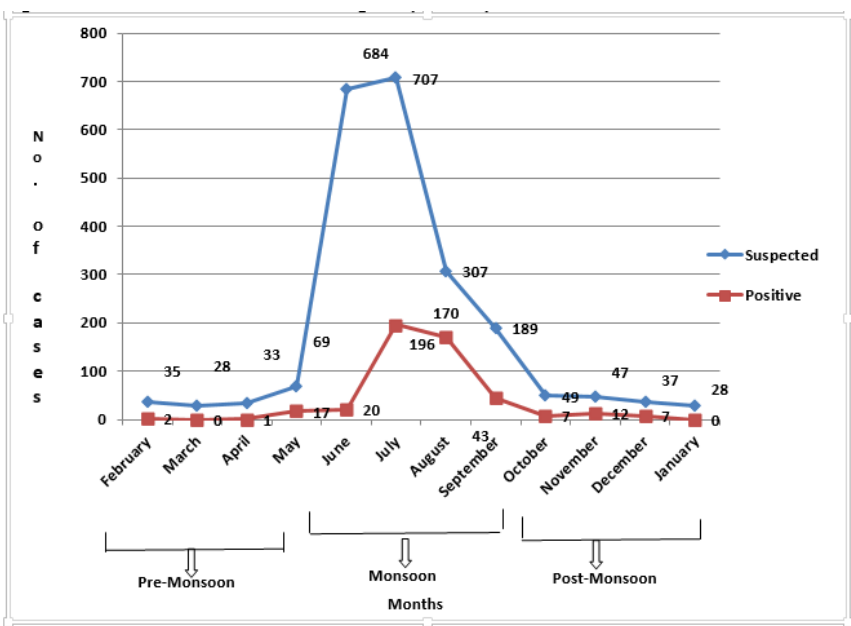

Fig. 3: Seasonal/ month wise distribution of Dengue suspects and positives

\section{Conclusion}

The present study found seroprevalence of dengue infection to be critical in the study setting and identifies paediatric group being most vulnerable for infection and also identifies monsoon season as the most favourable season for transmission of disease. Need to strengthen integrated vector control measures during rainy season with special attention to personal protection measures among children.

\section{References}

1. World Health Organization. Comprehensive Guidelines for Prevention and Control of Dengue and Dengue Haemorrhagic Fever. New Delhi;2011.

2. George S, Soman RS. "Studies on dengue in Bangalore City: Isolation of virus from man and mosquitoes". Indian J Med Res. 1975;63:396-401.

3. Kaur H, Prabhakar H, Mathew P, Marshalla R, Arya M. "Dengue haemorrhagic fever outbreak in OctoberNovember 1996 in Ludhiana, Panjab, India”. Indian J Med Res. 1997;106:1-3.

4. Gupta E, Dar L, Narang P, Srivastava VK, Broor S. "Serodiagnosis of dengue during an outbreak at a tertiary care hospital in Delhi". Indian J Med Res. 2005;121:368.

5. Raut S, Patil A. "Dengue in and around Nagpur- Central India". Journal of evolution of medical and dental sciences. 2012;1(5):-853.
6. Bennett SN, Holmes EC, Chirivella M, Rodriguez DM, Beltran M, Vorndam V, Gubler DJ, McMillan WO. "Selection-driven evolution of emergent dengue virus". Mol Biol Evol. 2003;20(10):1650-58.

7. WHO Library Cataloguing in Publication Data Dengue Guidelines for diagnosis, treatment and control. 2009:58105.

8. Mustafa MS, Rastogi V, Jain S, Gupta V. "Discovery of fifth serotype of dengue virus (DENV-5): a new public health dilemma in dengue control". Medical Journal armed forces of India. 2015;7:67-70.

9. Huber K, Loan LL, Hoang TH, Teen TK, Roahain F and Failloux AB. "Aedes aegypti in South Vietnam ecology, genetic structure vectorial competence and resistance to insecticides". Southeast Asian J Trop Med Public Health 2003;34(1):81-86.

10. Mandell, Doughlas and Bennett's principle and practice of infectious diseases, 7th edition, Churchill Livingstone Elsevier, Philadelphia.2010;2:2133-56.

11. Normile D. "Surprising new dengue virus throws a spanner in disease control efforts". Science. 2013;342:415.

12. Tricou V, Hang TV, Quynh NV, Nguyen CV, Tran HT, Farrar J, et. al. "Comparison of two dengue NS1 rapid tests for sensitivity, specificity and relationship to viraemia and antibody responses". BMC Infect Dis. 2010;10:142.

13. Shepard DS, Halasa YA, Tyagi BK, Adhish SV, Nandan $\mathrm{D}$, Karthiga KS, et al. "Economic and disease burden of dengue illness in India". Am J Trop Med Hyg. 2014;91(6):1235-42. 
14. Deshkar ST. Raut SS, Khadse RK. "Dengue infection in central India: A 5 years study at a tertiary care hospital". Int J Res Med Sci. 2017;5:2483-9.

15. Biradar A, Kauser Y, Itagi I, Jamadar NA. "Dengue infection: Its prevalence with seasonal variations". Indian J Microbiol Res 2016;3(2):89-92.

16. Pruthvi D, Shashikala P, Shenoy V. "Evaluation of platelet count in dengue fever along with seasonal variation of dengue infection". J Blood Disorders Transf 2012;3(4):1-4.

17. Garg A, Garg J, Rao YK, Upadhyay GC and Sakhuja S." Prevalence of dengue among clinically suspected febrile episodes at a teaching hospital in North India". Journal of Infectious Diseases and Immunity 2011;3(5):85-89.

18. Biradar AM, Nadagir SD, Shankar MK and Naik TB. "Clinical profile and diagnostic parameters of dengue viral infection among children". Int. J. Curr. Microbiol. App. Sci 2016;5(9):725-732.

19. Neralwar A, Banjare B, Barapatre R. "Detection of NS1 antigen, $\operatorname{IgM}$ antibody for the diagnosis of Dengue infection in patients with acute febrile illness". Int J Res Med Sci 2015;3:2826-30.

20. Wadekar MD, Naik T B, Upadhya AK, Swarooparani NB. "Prevalence of Malaria, Enteric fever, Dengue and Rickettsial diseases in fever cases at tertiary care hospital". International journal of microbiology research. 2016;8(1):720-722.

21. Garg A, Gangane R, Asharani S, Sharanabasava. "Seroprevalence of Dengue in North Karnataka". JMSCR 2015;3(6):6192-6198.

22. Arunasree B, Uma P, Rajsekhar B. "Epidemiology of dengue fever in Srikakulam District, Andhra Pradesh". Journal of Evolution of Medical and Dental Sciences 2015;4(27):4599-4604.

23. Manthalkar PS, Peerapur BV. "Serodiagnosis of Dengue virus infection using ELISA in patients with suspected Dengue infection". Journal of Evolution of Medical and Dental Sciences 2015;4(62):10824-10828.

24. Mehta KD, Gelotar PS, Vachhani SC, Makwana N, SinhaM. "Profile of dengue infection in Jamnagar city and district, West India". WHO South-East Asia Journal of Public Health. 2014;3(1):72-74.

25. Ukey PM, Bondade SA, Paunipagar PV, Powar RM, Akulwar SL. "Study of seroprevalance of dengue fever in central India". Indian J Community Med. 2010;35(4):5179.

26. Girish BRJ, Madhuri KR. "A clinicomicrobiological study of dengue fever cases at Sri Siddhartha Medical College \& Hospital, Tumkur". Indian J Microbiol Res 2016;3(2):209-212.

27. Prakash B, Darshan D. "Catching dengue early: clinical features and laboratory markers of Dengue virus infection". JAPI 2015;63:38-41.

28. Shah GS, Islam S, Das BK. "Clinical and laboratory profile of dengue infection in children". Kathmandu University Med. J. 2006;13:40-4.

29. Anderson KB, Chunsutiwwat S, Nisalak A, Mameen P, Libarty D, Rothman AL. "Burden of symptomatic dengue infection in children at primary school in Thailand: a prospective study". Lancet. 2007;369:1452-59.

30. Kumar A, Rao CR, Pandit V, Shetty S, Bammigatti C, Samarasinghe CM. :Clinical manifestations and trend of dengue cases admitted in a tertiary care hospital, Udupi district, Karnataka". Indian J Community Med. 2010;35(3):386-90.

31. Kauser MM, Kalavathi GP, Radadiya M, Karthik M, Afreen A, Kumaraswamy RC et. al. "A study of clinical and laboratory profile of Dengue fever in tertiary care hospital in Central Karnataka, India”. GJMR-B 2014;14(5).

32. Madhumati R, Kavya ST, Amrutha A, et al. "Demographic profile of Dengue infections in Bangalore: An Observational Study". Internat J Clin Cases Invest 2014;5:6-14.

33. Chakravarti A, Kumaria R. "Eco-epidemiological analysis of dengue infection during an outbreak of dengue fever, India". Virol J 2005;2:32.

34. Gupta E, Dar L, Kapoor G, Broor S. "The changing epidemiology of dengue in Delhi, India". Virol J 2006;3:92.

35. Mandal SK, Ganguly J, Sil K, et al. "Clinical profiles of Dengue fever in a teaching hospital of Eastern India". Nat J Med Res 2013;31:73-76.

36. Singh J, Dinkar A, Atam V, Himanshu D, Gupta KK, Usman K, Misra R. "Awareness and outcome of changing trends in clinical profile of Dengue fever: A retrospective analysis of Dengue epidemic from January to December 2014 at a tertiary care hospital". Journal of the association of physicians of India. 2017;65:42-46. 